\title{
Workspace Optimization for Modular Off-site Assembly
}

\author{
Hosang Hyun ${ }^{1}$, Hyun-Soo Lee ${ }^{2}$, Moonseo Park ${ }^{2}$, Jeoung-Hoon Lee ${ }^{1}$, and Minjung Kim ${ }^{3 *}$ \\ ${ }^{1}$ PhD course Researcher, Department of Architectural Engineering, Seoul National University \\ ${ }^{2}$ Professor, Department of Architectural Engineering, Seoul National University \\ ${ }^{3}$ MS course Researcher, Department of Architectural Engineering, Seoul National University \\ ${ }^{4}$ Corresponding author's e-mail: kimminjung@snu.ac.kr
}

\begin{abstract}
Modular construction is getting more prevalent than the past because it is environmentallyfriendly construction method and it can reduce construction period and cost by manufacturing in factory. Modular unit is produced through assembly line where the intensive manufacturing process is conducted. The manufacturing process is a complicated operation that integrates the production movement with a complex activity precedence network (procedure). Although modular unit production is a sum of the general construction activity superimposed on a production line in modular factory, the activities should be conducted on station for the optimal cycle time and many activities are carried out in the modular unit. So there is spatial constraint in the manufacturing process and modular construction manager suffers from existing limitations such as space, workers, materials which are caused by intensive process. If the manager doesn't consider the workspace interference when establishing construction process, the efficiency of modular construction would be reduced. The object of this research is to suggest the method which optimize the number of workers for activities on the station and increase the productivity by inputting appropriate number of workers for minimum workspace interference.
\end{abstract}

\section{KEYWORDS}

Modular Construction; Workspace Optimization; Off-Site Assembly; Workspace Interference

\section{INTRODUCTION}

Modular construction has been applied widely in recent times because of its characteristics, such as environmentally-friendly, cost-effective construction process and shorter completion time (MBI, 2015). The Modular construction process is composed of off-site modular unit production and on-site construction. In the modular unit manufacturing process, the modular unit is produced through assembly line where intensive manufacturing process is performed. The manufacturing process is a sum of the general construction activities, which integrates the production movement with complex procedures (Alvanchi et al. 2012; Nasereddin et al. 2007). In case of continuous modular production type, the modular unit is manufactured on the assembly line which consists of several stations. The station contains the activities which are disposed and grouped based on the manufacturing schedule which assigns the time to carry out the activities to the stations (Mehrotra et al. 2005). The grouped activities should be conducted during the optimal cycle time of station (Nasereddin et al. 2007) and there should be activities conducted in modular unit which size typically $16 \mathrm{ft}$ wide with a total area of $1,200 \mathrm{ft}^{2}{ }^{2}$. Moreover, there is flexibility that the station of activities can be changed because the properties of modular 
unit, such as size, complexities and the elements installation place of modular unit, are different (Nasereddin et al 2007). So the activity group can't help changing and it make hard to plan the manufacturing schedule. Moreover, the workers must conduct various activities with moving between stations so the space planning of modular manufacturing should be planned depending on the modular unit. Therefore, when planning the schedule, the modular construction manager suffers from existing spatial constraints such as lack of work space, interference of workers and material placement which are caused by intensive manufacturing process (Alvanchi et al. 2011). Moreover, if the manager can't manage the construction schedule based on the work space and time, there should be the work space interference and the productivity would decrease. So the objective of this paper is to suggest the method which estimates the number of workers conducting the activities in modular unit to increase the productivity. The process of this research is as followed; (1) analyzing of workspace interference and workspace planning in general construction for application to modular construction by literature review; (2) development of the method to optimize the input workers considering workspace and work time (3) describing the expected result and future research for completing this research.

\section{RELATED RESEARCH}

To increase the productivity of modular production, many researches have been conducted. Nasereddin et al. (2007) developed the strategy for modelling the modular housing production based on the principle of lean construction. This research described the difference between conventional construction and modular construction and argued that the current modular manufacturing processes were conducted manually and similar to conventional construction so the efficiency of modular construction wasn't fully expressed. Moreover, the customization of modular construction increases the manufacturing complexity. The strategy model suggested the design approach of modular manufacturing factory using simulation tool based on general data of factory such as activity name, the number of stations and average process time. The factory design could be modified depending on the property of modular unit and the design also could be generated automatically. Merotra et al. (2005) argued that there have been the needs to develop the systematic guide line for old production factory and new factory design and suggested the way of designing the modular factory layout to increase the productivity. To optimize the factory layout, the information of manufacturing process was collected from the factory and extracted the input data for the layout design simulation. The data was classified as space requirement and proximity requirement. Based on the data, the value of each station's relationship was deducted and the location of station was decided by the value because it is efficient that the stations which are has high proximity value each other, are allocated nearby. In other words, the factory layout is designed depending on the relationship of stations and finally the shape of assembly line was determined. However, although the spatial issues in modular manufacturing process is important (Alvanchi et al. 2011), the objective of previous researches was to suggest the factory layout design based on the properties of activities and stations so the researches have limitations that the workspace for manufacturing the modular unit wasn't considered. In general construction, the workspace is regarded as key resource (Seman et al. 2013) and many researches were conducted to increase construction productivity by planning the schedule based on the workspace. Inefficiency of planning and managing the space utilization for activities could incur the work space interference (Akinci 2002; Riley and Sanvido 1997). The workspace interference has

created many problems such as reduced productivity, quality and delayed completion of 
construction (Akinci 2002; Riley and Sanvido 1997). Various definitions of workspace interference from previous researches were mostly converged on performing two different work activities in same space (Riley and Sanvido 1995). Akinci et al. (2002) represented the type of work space required by construction activities and suggested the way to automatically generate the project-specific activity space requirement by use of 4D production model information and by interpretation of generic space descriptions. The workspace interference between activities could be detected by the automated generation of the project-specific activity space requirement. However, the previous researches of general construction have the limitation that the researches can't consider the use of workspace based on time which is required to complete the activities. In case of modular manufacturing process, various activities are conducted simultaneously on stations because the stations have the assigned cycle time. If the factory manager couldn't manage the workspace used by workers based on activity completion time, the workspace interference would occur and it would delay the working hour of stations and finally the efficiency of modular construction would be reduced.

\section{METHODOLOGY}

To optimize the number of workers conducting activities, this research will use Genetic Algorithm (G.A). The concept of G.A has been popular in various disciplines such as constrained and unconstrained optimization, reliability optimization, and scheduling and sequencing (Jang et al. 2007). Jang et al. (2007) used G.A for designing construction material layout while taking the complicated relationship between construction materials into account. The way of using G.A is applicable to this research because optimizing material assignment is accomplished considering spatial limitation. Moreover, the optimization method of G.A is to estimate the optimal solution through combining the variables value and the characteristics of G.A are including the complicated relationship of variables, constrained optimization and optimizing the schedule. The method of this research is to suggest the optimized combination of workers and to estimate the productivity based on the combination so G.A would be adopted to estimate the input workers.

\section{WORKSPACE PLANNING}

This section discusses the method for the workspace planning which optimizes the number of workers conducting activities. Although the activities could be conducted more quickly than optimal cycle time by inputting more workers, the modular unit can't move toward next stage. Therefore, if the manufacturing process isn't conducted by optimized number of workers, the productivity couldn't increase. The workspace planning process deals with characteristic of modular manufacturing process. Figure 1 presents a schematic diagram for the workspace planning process. The workspace planning process consists of three phases: (1) the characteristics of assembly station should be considered for planning workspace. The optimal cycle time affects the assembly line of each factory and the number of activities which are carried out in stations. So it is important to take the optimal time into account because the number of workers inputted for work changes depending on the cycle time and reasonable number of workers based on the cycle time is directly related to increasing the productivity. Then it is assessed whether the activities on station could be conducted simultaneously or not because the activities can be conducted in the same time with reasonable number of workers, it can 
reduce the total manufacturing time and it can increase the productivity. In this phase, if there are the activities, it is assumed that the activities are carried out in the same time.

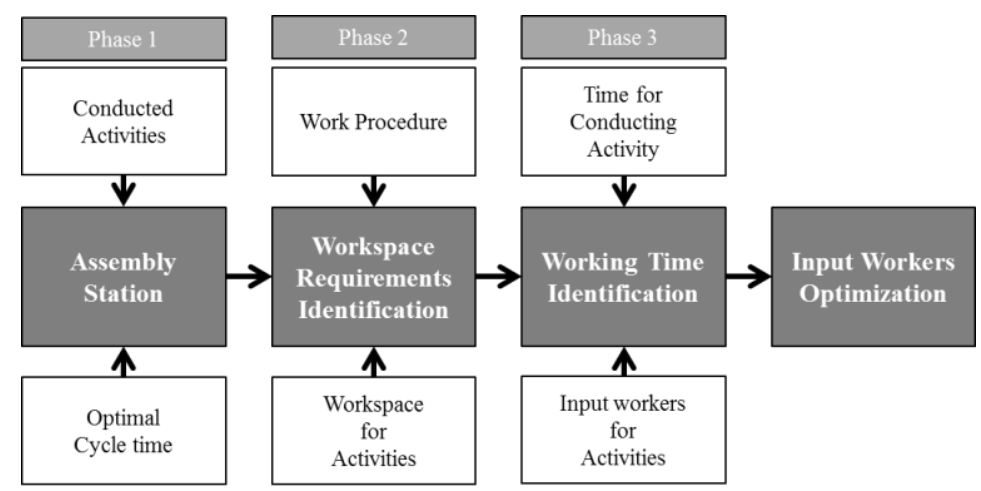

Figure 1. Work space planning process

(2) The unit workspace for minimum workers accomplishing the activities is identified. Choi et al. (2014) suggested the method for assessing unit workspace for activities. The workspace consists of the unit workspace. The unit work represents the work area conducted in unit workspace at a time. Figure 2 is the illustration of assessing working space for activities.

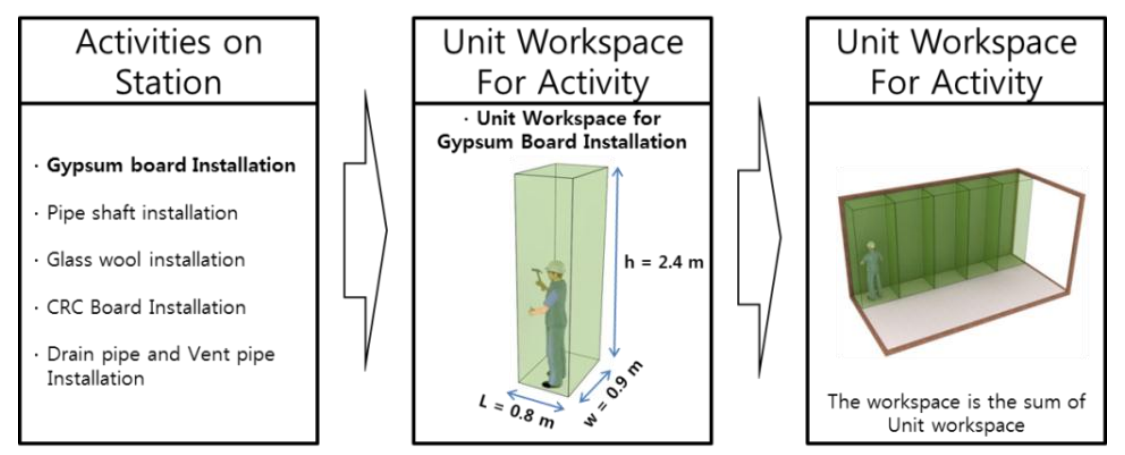

Figure 2. Assessment of Workspace (Choi et al. 2014)

Figure 3 shows the units which are applied for optimizing the input worker and workspace interference, such as the unit work area, the unit work space and the time for the unit work.

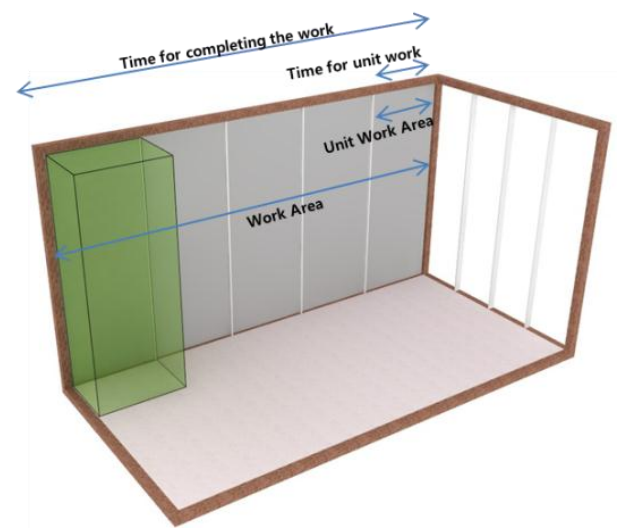

Figure 3. The units in Workspace Planning 
(3) The time for carrying out the unit work is assessed. The sum of time for unit work is the time for completing the work. The times could be measured manually by monitoring the activities. Then, the number of input workers is optimized considering optimal cycle time of station. Choi et al. (2014) developed the concept for classifying the unrealistic workspace problem which means that if the schedules of the activities don't overlap, the workspace problem wouldn't occur. This paper modified the concept for modular manufacturing.

\section{Assembly Station}

This research adopted the continuous modular production type. In case of continuous type, modular production factory has assembly line(s) and the line consists of stations. On the stations, work activities are conducted. The manufacturing process is finished when the last activity is completed on last station. If the activities on specific station can be carried out in the same time, the optimal cycle time of the station can be reduced, which is related to productivity. So it is assessed that the activities can be conducted simultaneously. For example the activity conducting finish work of left side of wall in modular unit proceeds with the work of right side of window installation. If there are the activities, the next phases are conducted. Table 1 is the example which shows the activities of specific station.

Table 1. Example of Activities conducted on station.

\begin{tabular}{|c|c|c|c|c|c|c|}
\hline Station & Type & $\begin{array}{l}\text { Activity } \\
\text { Number }\end{array}$ & Activity Name & Location & $\begin{array}{c}\text { Possible } \\
\text { simultaneous } \\
\text { work } \\
\end{array}$ & $\begin{array}{c}\text { Possible } \\
\text { Interference }\end{array}$ \\
\hline \multirow{5}{*}{$\begin{array}{c}\text { Station } \\
3\end{array}$} & Structure & 1 & $\begin{array}{l}\text { Gypsum Board } \\
\text { Installation }\end{array}$ & Inside South Wall & 2 & 2 \\
\hline & Structure & 2 & Pipe Shaft Installation & Inside East Wall & 1 & 1 \\
\hline & Structure & 3 & $\begin{array}{l}\text { Glass Wool } \\
\text { Installation }\end{array}$ & Outside East Wall & & \\
\hline & Structure & 4 & $\begin{array}{l}\text { CRC Board } \\
\text { Installation } \\
\end{array}$ & Outside East Wall & & \\
\hline & Facility & 5 & $\begin{array}{l}\text { Drain Pipe and Vent } \\
\text { Pipe Installation }\end{array}$ & Inside East Wall & & \\
\hline
\end{tabular}

In the Table 1 the activity 1, 2 can be conducted in the same time when considering the working procedure and location but the work interference is expected. So the workspace requirement and working time of activity 1, 2 should be identified to optimize input worker for minimizing work interference.

\section{Workspace Requirement Identification}

The workspace requirement for the execution of activities is identified in this phase. Choi et al. (2014) suggested the method for assessing working space for activities. This paper modified the method for modular manufacturing and Figure 2 is the example of working space for the execution of specific activity. For assessing the workspace, the activities conducted on station should be identified. Then, the minimum space for completing the specific activity is assessed. If the workspace is used more than one worker, the workspace should be planned for the number of workers. The workers are grouped and the group is the minimum unit for conducting activity. The workgroup or worker is combined for optimizing the input worker and workspace interference. After the workspaces for specific activities are measured, the work area is divided and the unit workspace is assigned in front of the object. 


\section{Working Time Identification}

In this phase the time for carrying out the activities is identified. The whole working area for specific activity is divided by the unit workspace. The time for conducting work area is the sum of unit time which is consumed for conducting a unit work area by one worker or work group. Then the minimum workers for executing the specific activity are estimated and the input workers for the activity are identified by the multiplication of the minimum workers. For example, if the two times of minimum workers are inputted, the time for the activity is the half of original time. However, modular unit has the spatial limitation so the input workers are controlled. If the workspace interference is expected because of conducting activities simultaneously, the time for unit work is controlled to avoid workspace interference. The more workers are inputted the shorter the work time is for activity. If one of the activities can be completed before the interference occurs, the interference wouldn't affect the activities. However, as mentioned above, the cycle time is defined so reasonable workspace interference would be allowed when the productivity wouldn't be affected.

\section{Input Workers Optimization}

This section discusses the method to optimize the input workers executing activities based on the previous phases. The method is divided two steps. First, the number of input workers is estimated based on unit workspace and working time. As mentioned above, the maximum number of input workers is defined by the spatial property of modular unit. Second step is to assess the productivity of workers. The more workers are inputted, the shorter working time is. However, the modular unit move to next station depending on the cycle time so it is important to estimate the appropriate number of workers. Finally, the number workers of activities are decided depending on the result of productivity.

$$
\text { Productivity }=\frac{\text { Working Area }}{\text { Input Workers }}
$$

The number of workers executing activities is the sum of working group which consist of the worker(s) conducting the specific activity. The working group combination can vary depending on working time and workspace interference. Table 1 shows example of working group combination (Not real data). If the workspace interference occurs between activities, the activity which arrived late should stop working until other activity is completed. The workspace interference can be regulated by changing the number of working group. For example, if the workspace interference is expected between A activity and B activity, the workgroup is inputted more to A or B activity to avoid workspace interference by controlling working speed. To maintain high productivity, proper workspace interference could be allowed if the activities could be completed in the optimal cycle time of station. For optimizing the number of workers, the number of combination is randomly controlled using G.A. and various combinations are generated. Each combination's productivity is estimated automatically and averaged for the productivity of station. In various combinations, there would be the combination which has shortest working time and highest productivity. The combination would be adopted. 
Table 1. This is an example of working group.

\begin{tabular}{|c|c|c|c|c|c|c|c|c|}
\hline Station & $\begin{array}{l}\text { Activity } \\
\text { Number }\end{array}$ & $\begin{array}{l}\text { Activity } \\
\text { Name }\end{array}$ & $\begin{array}{l}\text { Work } \\
\text { Area }\end{array}$ & $\begin{array}{c}\text { Minimum } \\
\text { Worker }\end{array}$ & Interference & Combination & Productivity & $\begin{array}{c}\text { Total } \\
\text { Productivity }\end{array}$ \\
\hline \multirow{5}{*}{3} & 1 & $\begin{array}{l}\text { Gypsum } \\
\text { Board } \\
\text { Installation }\end{array}$ & $0 \mathrm{~m} \times 0 \mathrm{~m}$ & 0 & 2 & 0 unit & 0 & \multirow{5}{*}{0} \\
\hline & 2 & $\begin{array}{l}\text { Pipe Shaft } \\
\text { Installation }\end{array}$ & $0 \mathrm{~m} \times 0 \mathrm{~m}$ & 0 & 1 & 0 unit & 0 & \\
\hline & 3 & $\begin{array}{l}\text { Glass Wool } \\
\text { Installation }\end{array}$ & $0 \mathrm{~m} \times 0 \mathrm{~m}$ & 0 & & 0 unit & 0 & \\
\hline & 4 & $\begin{array}{l}\text { CRC Board } \\
\text { Installation }\end{array}$ & $0 \mathrm{~m} \times 0 \mathrm{~m}$ & 0 & & 0 unit & 0 & \\
\hline & 5 & $\begin{array}{l}\text { Drain Pipe } \\
\text { and Vent Pipe } \\
\text { Installation }\end{array}$ & $0 \mathrm{~m} \times 0 \mathrm{~m}$ & 0 & & 0 unit & 0 & \\
\hline
\end{tabular}

\section{EXPECTED RESULT AND CONCLUSION}

The research of this paper is progressing so the optimized input worker isn't estimated. The objective of this paper is to suggest the method for future research. The expected contributions of this research are as follows; (1) the minimized workspace interference could increase work efficiency (2) the method for optimizing the input worker would be used for assigning the optimal cycle time of station. (3) By accomplishing activities simultaneously, the working time could decrease, which make more activity carried out on station. It means that the number of stations could be reduced and the productivity would increase. For this method more research should be conducted. The activities which could be carried out simultaneously are assigned on same station and the assembly line should be redesigned for the efficient assignation. For extracting the empirical result, the database which includes working time, workspace should be established.

\section{ACKNOWLEDGEMENT}

This research was supported by a grant (14RERP-B082884-01) from Housing Environment Research Program funded by Ministry of Land, Infrastructure and Transport of Korean government.

\section{REFERENCES}

Akinci, B., Fischer, M., \& Kunz, J. (2002). “Automated generation of work spaces required by construction activities." Journal of construction engineering and management, 128(4), 306315.

Alvanchi, A., Azimi, R., Lee, S., AbouRizk, S. M., \&Zubick, P. (2011). "Off-site construction planning using discrete event simulation.” Journal of Architectural Engineering, 18(2), 114-122.

Choi, B., Lee, H. S., Park, M., Cho, Y. K., \& Kim, H. (2014). "Framework for Work-Space Planning Using Four-Dimensional BIM in Construction Projects." Journal of Construction Engineering and Management, 140(9).

Mehrotra, N., Syal, M., \& Hastak, M. (2005). "Manufactured housing production layout design." Journal of architectural engineering, 11(1), 25-34.

Modular Building Institute (2015). "Commercial modular construction report." www.modular.org, USA, 1-23. 
Nasereddin, M., Mullens, M. A., \& Cope, D. (2007). "Automated simulator development: A strategy for modeling modular housing production." Automation in Construction, 16(2), 212-223.

Jang, H., Lee, S., \& Choi, S. (2007). "Optimization of floor-level construction material layout using Genetic Algorithms.” Automation in construction, 16(4), 531-545.

Kaming, P. F., Holt, G. D., Kometa, S. T., \&Olomolaiye, P. O. (1998). Severity diagnosis of productivity problems - a reliability analysis. International Journal of Project Management, 16(2), 107-113.

Mullens, M. A. (2011). Factory Design for Modular Homebuilding: Equipping the Modular Factory for Success. Constructability Press.

Riley, D. R., \& Sanvido, V. E. (1995). "Patterns of construction-space use in multistory buildings." Journal of Construction Engineering and management, 121(4), 464-473.

Riley, D. R., \& Sanvido, V. E. (1997). "Space planning method for multistory building construction." Journal of Construction Engineering and Management, 123(2), 171-180.

Seman, M. A. M., Hanafi, M. H., \& Abdullah, S. (2013). "Main Factors Lack of Workspace Planning That Causes Workspace Conflict on Project Environment: Industrialised Building System In Malaysia." Australian Journal of Basic and Applied Sciences, 7(6), 408-419.

Thabet, Walid Y., and Yvan J. Beliveau. "Modeling work space to schedule repetitive floors in multistory buildings." Journal of Construction Engineering and Management 120.1 (1994): 96-116. 